\title{
OBSERVATÓRIO DA DEMOCRACIA DE ALFENAS/MG: POSSIBILIDADES E DESAFIOS DA EDUCAÇÃO EM DIREITOS HUMANOS ATRAVÉS DO PARLAMENTO JOVEM
}

\author{
OBSERVATORY OF DEMOCRACY OF ALFENAS/MG: THE \\ POSSIBILITIES AND CHALLENGES OF HUMAN RIGHTS \\ EDUCATION THROUGH THE YOUTH PARLIAMENT
}

\author{
Gleyton Trindade \\ ORCID: https://orcid.org/0000-0002-8633-1884 \\ Francis Lázaro Júnior \\ ORCID: https://orcid.org/0000-0002-3420-6491 \\ Thiago Silame \\ ORCID: https://orcid.org/0000-0001-7018-5694
}

\section{Resumo}

Este texto constitui um relato sobre a experiência do projeto de extensão Observatório da Democracia com a implementação do Parlamento Jovem na cidade de Alfenas/MG. O projeto pretendeu valorizar espaços de formação e educação política democrática e educação em direitos humanos utilizando o Parlamento Jovem como ação articuladora. A metodologia consistiu no planejamento e realização compartilhada de oficinas, palestras, plenárias e materiais informativos em parceria com entidades civis e Câmara Municipal. Este relato também reflete sobre as possibilidades e os limites de uma ação de extensão em educação em direitos humanos articulada através do Parlamento Jovem. Entre as possibilidades, o aproveitamento da estrutura e eixos temáticos desenvolvidos pela Assembleia de Minas, a articulação entre poder legislativo, universidade e associações civis. Entre os desafios, o ainda baixo investimento das Câmaras em educação política e a consequente desarticulação com as escolas em ações educativas.

Palavras-chave: Educação Política; Democracia; Parlamento Jovem.

Data recebimento: $04 / 02 / 2021$

Data de aceite: $22 / 06 / 2021$

\begin{abstract}
This text is a report on the experience of the outreach project Observatory of Democracy, by implementing the Youth Parliament in Alfenas / MG. The project aimed to enhance spaces for training and for political democratic education and human rights education, articulating actions through the Youth Parliament. Its methodology consisted of planning and sharing workshops, lectures, plenary sessions and informational materials in partnership with civil entities and the City Council. It also reflects on the possibilities and limits of an outreach action in human rights education articulated through the Youth Parliament. Among the possibilities, the use of the structure and the thematic axes developed by the Assembly of Minas, the articulation between the legislative power, university and civil associations. Among the challenges, the low investment of the Chambers in political education and the consequent disarticulation of schools in educational actions.
\end{abstract}

Keyword: Political Education; Democracy; Youth Parliament .

* Professor da Universidade Federal de Alfenas (UNIFAL), Alfenas - MG, Brasil. E-mail: gleytontrindade@hotmail.com

** Aluno de Mestrado da Universidade Federal de Itajubá (UNIFEI), Itajubá - MG, Brasil. E-mail: francislj.cs@gmail.com

*** Professor da Universidade Federal de Alfenas (UNIFAL), Alfenas - MG, Brasil. E-mail: thiago.silame@gmail.com 


\section{Introdução}

O Observatório da Democracia de Alfenas/MG foi implementado como projeto de extensão a partir de 2018, numa parceria da Universidade Federal de Alfenas, Câmara Municipal de Alfenas e associações civis da regiãoi. Este projeto de extensão, entre os anos de 2018 e 2019, pretendeu auxiliar e fomentar o estabelecimento de canais de diálogo entre o conhecimento produzido nas universidades, representantes dos legislativos municipais e jovens da comunidade em ações que pretendem valorizar espaços de formação e educação política democrática. Parte, portanto, do pressuposto de que a dimensão política da vida em sociedade constitui uma das mais importantes e influentes esferas de nossa ação, merecendo, portanto, constituir-se como objeto de debate, reflexão, educação e aprimoramento para o desenvolvimento de nossa democracia. Neste aspecto, esta proposta extensionista pretende se institucionalizar como ação permanente vinculada ao curso de Ciências Sociais da Universidade Federal de Alfenas, atuando nos temas da defesa dos direitos fundamentais, da justiça e da educação democrática.

A origem do projeto Observatório da Democracia está na demanda por ações de educação política por parte de associações civis da região e na demanda da Câmara Municipal de Alfenas pela implementação do Parlamento Jovem de Minas (PJ). A opção do projeto foi, então, por uma ação que, além de implementar o PJ, pudesse utilizá-lo como ação articuladora de um projeto capaz de desenvolver outras ações de educação política. Assim, pretendeu-se estabelecer uma ação de educação em política e direitos humanos que utilizasse o Parlamento Jovem de Minas como elemento articulador. Passadas duas edições do projeto, é possível realizar uma reflexão sobre as possibilidades e limites de um projeto de educação em direitos humanos que adotou tal estratégia. As possibilidades envolvem a articulação entre agentes públicos e associações civis, a estrutura e material oferecidos pela Assembleia de Minas ao PJ. Os limites envolvem o ainda baixo envolvimento e investimento de boa parte das Câmaras Municipais em ações educativas.

\section{A participação política no Brasil democrático}

Nesta seção sobre participação política, seguimos as indicações e reflexões desenvolvidas por Avritzer (2006).

De acordo com Avritzer (2006), o sistema político brasileiro resultado da Constituição de 1988 é um sistema híbrido que incorporou, em sua organização, amplas formas de participação política tanto no plano federal como no plano local. Duas formas principais de participação se iniciaram com a Constituição de 1988: a primeira trata da participação direta por meio da expressão da soberania em referendos, plebiscitos e iniciativas populares. A segunda forma de participação está centrada no nível local e se prolifera graças à incorporação da participação exigida por alguns pontos das políticas sociais da Constituição de 1988, em particular alguns capítulos da seguridade social e da reforma urbana. O que acontece é que a Constituição de 1988 propõe, em sua arquitetura, uma combinação entre formas de representação e de participação. Essa combinação fica expressa na redação do artigo 14, incisos I, II, III, que assegura que "[a] soberania popular será exercida pelo sufrágio universal e pelo voto direto e secreto, 
com valor igual para todos, e, nos termos da lei, mediante: plebiscito; referendo [e] iniciativa popular" (BRASIL, 2020, p. 18). Desta forma, o Brasil, a partir de 1988, passa a integrar um grupo seleto de países que não têm, na representação política, sua única forma de expressão política institucionalizada.

Avritzer (2006) entende que a tentativa de combinação entre participação e representação também é prevista para estados e municípios no artigo 27 da Constituição de 1998, que estabelece que "[a] lei disporá sobre a iniciativa popular no processo legislativo estadual" (BRASIL, 2020, p. 25). Também no artigo 29, incisos XII e XIII, sobre os Municípios, que dispõe que o Município se rege por lei orgânica

[...] atendidos os princípios estabelecidos nesta Constituição, na Constituição do respectivo Estado e os seguintes preceitos: “... iniciativa popular de projetos de lei de interesse específico do município da cidade ou de bairros, através de manifestação de, pelo menos, cinco por cento do eleitorado (...). (BRASIL, 2020, p. 27)

Nota-se que a exigência de participação não se esgota nos níveis de Executivo, mas abrange também o Legislativo. O artigo 61 da Constituição de 1998 assegura que

[a] iniciativa popular pode ser exercida pela apresentação à Câmara dos Deputados de projeto de lei subscrito por, no mínimo, um por cento do eleitorado nacional distribuído pelo menos por cinco estados, com não menos de três décimos por cento dos eleitores de cada um deles. (BRASIL, 2020, p. 46)

Assim, as formas de exercício direto da soberania popular, referendo, plebiscito e iniciativa popular estão por toda parte do texto da Constituição de 1988, ainda que tenham sido pouco exercidas no Brasil democrático.

Avritzer (2006) destaca outra forma de participação prevista na Constituição de 1988, que é a de atores ou entidades da sociedade civil na deliberação sobre políticas públicas. Essas formas, presentes nos capítulos da seguridade social e da reforma urbana, tornaram-se amplamente difundidas no Brasil democrático. Com relação à gestão das políticas públicas, o artigo 194, parágrafo único, inciso VII, sobre a seguridade social, assegura o "caráter democrático e descentralizado da administração, mediante gestão quadripartite, com participação dos trabalhadores, dos empregadores, dos aposentados e do governo nos órgãos colegiados" (BRASIL, 2020, p. 103). Já o artigo 204, inciso II, sobre a Assistência Social, prescreve "a participação da população, por meio de organizações representativas, na formulação das políticas e no controle das ações em todos os níveis" (BRASIL, 2020, p. 108). E, finalmente, o artigo 227, parágrafo $1^{\circ}$, acerca da Família, Criança, do Adolescente e do Idoso, entende que "[o] Estado promoverá programas de assistência integral à saúde da criança e do adolescente, admitida a participação de entidades não-governamentais [...]" (BRASIL, 2020, p. 217). Assim, o processo constituinte se tornou a origem de um conjunto de instituições híbridas, que começaram a ser normatizadas nos anos 1990, tais como os conselhos de política e tutelares ou formas de participação a nível local. 
As instituições participativas que realmente se multiplicaram pelo país, de acordo com Avritzer (2006), são os conselhos de políticas e os orçamentos participativos. Os conselhos de política são fruto de legislações especiais ou infraconstitucionais que surgem para regulamentar os artigos da Constituição de 1988 sobre a saúde, a assistência social, a criança e o adolescente e as políticas públicas ${ }^{\mathrm{ii}}$, ao passos que as principais legislações participativas tiveram início a partir da lei Orgânica da Saúde (LOS), da Lei Orgânica da Assistência Social (LOAS), do Estatuto da Criança de do Adolescente e do Estatuto da Cidade. Cada uma delas estabelecia a participação de uma forma diferente, porém, a partir dos anos 1990, todas essas formas ficaram conhecidas por Conselhos. Desta forma, podemos definir conselhos como:

[...] instituições híbridas nas quais há participação de atores do Executivo e de atores da sociedade civil relacionados com a área temática na qual o conselho atua. $\mathrm{O}$ formato institucional dos conselhos, em todas as áreas mencionadas, é definido por legislação local, ainda que os parâmetros para a elaboração dessa legislação sejam dados pela legislação federal. Todos esses conselhos adotam a paridade como princípio, ainda que a forma específica da paridade varie de área temática para área temática (AVRITZER, 2006, p. 38).

Dessa forma, Avritzer (2006) destaca que existe uma gama de evidências do funcionamento exitoso dos conselhos em algumas grandes cidades e no papel desempenhado por alguns conselhos nacionais, como o da saúde e da assistência social. Além dessas instituições exigidas pela própria Constituição, outras instituições participativas como os Orçamentos Participativos e consultas públicas foram elaborados e desenvolvidos por poderes executivos e legislativos em todo o país, abrindo um vasto campo de participação institucional. Essa abertura à participação política democrática suscitou também uma questão fundamental: a da educação política para os cidadãos que participam ativamente de um regime democrático.

\section{Educação política e o Parlamento Jovem de Minas}

Alguns estudiosos têm, há algum tempo, chamado a atenção para ações de educação política que possam revigorar a cultura política e contribuir para o entendimento dos processos políticos (ALMOND; VERBA, 1989). Entende-se que a formação dessa cultura pode ocorrer de forma dinâmica, desde a infância, nas interações entre gerações, na escola e na relação com o Estado, envolvendo processos informais de educação, mas também processos formais. Daí a observação de que o processo de educação política envolve também um elemento de "letramento político". No campo da educação política, letramento político é definido como um "processo de apropriação de práticas, conhecimentos e valores para a manutenção e aprimoramento da democracia" (COSSON, 2008, p. 195). Como processo, o letramento político estaria em contínua transformação, atuando tanto sobre os sujeitos quanto sobre a comunidade na qual estão inseridos. Seria, portanto, um processo simultâneo de aprendizagem e aquisição de conhecimento e valores. Dentre as práticas de educação política formais no Brasil, frequentemente se apontam essas características do letramento político nas experiências de Parlamento Jovem, entendido como um método de educação política para jovens que desenvolve uma percepção múltipla do que 
é a vida política, com vistas à promoção do envolvimento dos jovens com as questões políticas na escola, na comunidade e na cidade (FELIPPE, 2012).

No caso específico do Parlamento Jovem de Minas, trata-se de ação desenvolvida pela Escola do Legislativo da Assembleia Legislativa de Minas Gerais, que visa à formação política de estudantes do ensino médio dos municípios mineiros, oferecendo-lhes uma oportunidade de conhecer melhor a política e os instrumentos de participação. Sua primeira edição ocorreu em 2004 e possui periodicidade anual. Seu desenvolvimento se dá pela discussão de um tema específico, escolhido por seus participantes. Esse tema pauta pesquisas, estudos e debates, promovidos no decorrer do projeto, objetivando a elaboração de propostas a serem encaminhadas ao Poder Legislativo.

A partir de 2010, o projeto se expandiu e passou a ser realizado em parceria com câmaras municipais do interior do Estado. As câmaras dos municípios participantes, sob a orientação de servidores da ALMG, mobilizaram escolas do ensino médio e fizeram parcerias com universidades, órgãos públicos, empresas e organizações da sociedade civil, para a implementação do projeto, formando uma extensa rede de formação política e educação legislativa em todo o Estado (CASTRO; FREITAS, 2017). Nos quatro anos seguintes, o projeto se organizou em duas etapas: uma municipal, com atividades de formação, debates e elaboração de proposições apresentadas pelos jovens nos parlamentos municipais, e a etapa estadual, em Belo Horizonte, que reunia jovens representantes de cada cidade participante, na ALMG, para debater e aprovar as propostas oriundas dos municípios.

A partir de 2013, o PJ de Minas foi regionalizado, com vistas à sua expansão. Passou a incluir uma etapa intermediária entre a etapa municipal e a estadual: a etapa regional. $\mathrm{Na}$ etapa regional, as propostas oriundas da etapa municipal são consolidadas num documento construído conjuntamente, passando-se a traduzir os interesses do polo e não mais de municípios. Criou-se, assim, uma articulação dos municípios, em polos definidos por proximidade geográfica, o que permitiu um trabalho cooperativo entre eles (CASTRO; FREITAS, 2017 , p. 14). No caso específico da cidade de Alfenas, sua participação foi iniciada com o projeto Observatório da Democracia a partir de 2018, vinculada ao polo de Varginha.

É interessante notar que estudos sobre experiências de educação política como o PJ apontam que programas de educação cívica nas escolas, por exemplo, são capazes de aumentar o conhecimento político dos alunos, bem como promover atitudes mais democráticas entre eles. Além disso, as ações tornam os alunos mais dispostos a debater o seu ponto de vista e predispostos a participar (CAMPBELL, 2008).

Programas fora das escolas, dirigidos à comunidade como um todo, também têm efeitos substantivos na produção de conhecimento político, eficácia política, na participação e na tolerância. Os participantes desses programas também se tornam mais moderados em suas opiniões políticas. Além disso, tais efeitos não seriam apenas diretos, mas também indiretos, uma vez que são transmitidos às redes mais próximas pelos participantes (FINKELL; SMITH, 2010). Os resultados dessas pesquisas fortaleceram, especialmente nos países de democracias avançadas, os programas de educação política no processo de socialização política, promovendo conhecimento, atitudes e comportamentos favoráveis à estabilidade e ao desempenho 
da democracia. É necessário destacar que este tipo de iniciativa é particularmente importante em democracias não consolidadas como a nossa, onde existe uma cultura política democrática ainda em processo de formação e que tem de lidar com um quadro histórico de exclusão e desrespeito aos direitos fundamentais.

\section{O Observatório da democracia}

O projeto de extensão Observatório da Democracia surgiu no âmbito da Universidade Federal de Alfenas em 2018 como forma de viabilizar diálogo reflexivo e práticas educativas em política e democracia. Sua estrutura foi pensada para viabilizar a implementação do Parlamento Jovem Minas, mas também para utilizar o PJ como eixo articulador para outras ações possíveis, com objetivos descritos a seguir.

Como objetivo geral, fomentar e desenvolver espaços de discussão, reflexão e intercâmbio de informações que busquem contribuir para a formação sobre a realidade política e social, o auxílio na defesa dos direitos humanos e fundamentais e articulação de ações de pesquisa e extensão com gestores públicos municipais e sociedade.

E como objetivos específicos:

1. Possibilitar a formação de atores políticos e sociais para a participação democrática em organizações civis e movimentos sociais, conselhos municipais e no acompanhamento da implementação de políticas públicas locais.

2. Fomentar a participação política da juventude local com vistas ao auxílio na implementação o Estatuto da Juventude e das Conferências Municipais da Juventude no sul de Minas.

3. Possibilitar a aproximação dos discentes da Unifal-MG da realidade local, das demandas de uma sociedade democrática e da formação acadêmica fundamentada no respeito aos direitos humanos e na superação de condições de exclusão social.

4. Compartilhar conhecimentos formais (e não formais) e experiências entre Universidade, professores de diferentes áreas, estudantes e os participantes;

5. Produção de material acadêmico e didático que valorize a memória e o patrimônio histórico-cultural local;

6. Auxiliar na implementação, por parte da Câmara Municipal de Alfenas, do Parlamento Jovem desenvolvido pela Assembleia Legislativa de Minas Gerais.

É do cientista político Robert Dahl (1998) a afirmativa de que os regimes democráticos impõem mais responsabilidades sobre as pessoas comuns do que fazem os regimes autoritários e totalitários. Isto porque a democracia, como "governo do povo" em condições de "pluralidade social", exige de seus cidadãos participação política, conhecimento político básico, entendido como a base cognitiva a partir da qual os cidadãos podem tomar suas decisões e a presença de determinadas atitudes em relação aos outros cidadãos, o que pode ser designado como "tolerância democrática". A partir daí, uma problematização se coloca imediatamente: como promover nos cidadãos de uma democracia tais aptidões compatíveis com as exigências da preservação e consolidação de um regime democrático de direito? 
Para além dos aspectos estruturais, tais como condições econômicas e familiares que interferem na formação do sujeito democrático, estudiosos têm chamado a atenção para a necessidade e a importância da implementação de programas de educação política democrática, além de documentos que balizam políticas públicas no país, como o Plano Nacional de Extensão Universitária e o Plano Nacional de Educação em Direitos Humanos.

Este projeto foi inspirado numa série de ações de extensão que vinculam a produção do conhecimento científico a uma possibilidade real de atuação e intervenção na sociedade, no caso, vinculam o saber produzido nas universidades à formação de sujeitos ativos e críticos do ponto de vista social, humano e democrático. Procura estabelecer, portanto, a via de ligação entre o conhecimento acadêmico e o 'popular' e, mais que isso, fazendo um caminho duplo, onde o saber não fique restrito à Universidade (FREIRE, 1998). Esta proposta também se assenta no conhecimento produzido por várias pesquisas que têm demonstrado a eficiência desse tipo de iniciativa em promover competência cívica, especialmente o conhecimento político ${ }^{\mathrm{iii}}$.

A origem dessa proposta extensionista pode ser encontrada numa rede de cidadãos, profissionais da educação e agentes públicos. As redes, por serem multiformes, permitem a aproximação entre atores sociais diversificados, dos níveis locais aos mais globais e dos diferentes setores, o que acarreta aos sujeitos a passagem da defesa de um sujeito identitário único para a defesa de um sujeito plural (SCHERRERWARREN, 2006, p. 116). Isto significa compreender os direitos de cidadania em sua transversalidade, ou seja, a defesa da indivisibilidade dos direitos e a articulação das lutas pelos direitos humanos em suas várias dimensões (humanos, econômicos, sociais, culturais, ambientais).

A concepção da presente proposta de ação extensionista decorre deste caminho trilhado pelos movimentos sociais brasileiros rumo à transversalidade dos direitos. Por isto mesmo, a interdisciplinaridade torna-se obrigatória para esta proposta, que mobiliza profissionais de diferentes áreas como Sociologia, Direito, Ciência Política, Educação, Meio Ambiente.

Fomenta-se a relação entre ensino, pesquisa e extensão durante todas as etapas da realização do projeto, seja na proposta de organização participativa das atividades, seja na atuação dos graduandos extensionistas nos trabalhos de ensino e exploração da realidade local vinculadas à própria natureza da ação. As atividades de pesquisa são promovidas também em relação aos próprios participantes das ações, visando a elaboração de produtos acadêmicos que explorem a realidade regional do ponto de vista político e social, com base na reflexão desenvolvida durante a realização das atividades.

De maneira mais geral, este projeto se vincularia a ações de pesquisa já desenvolvidas por sua equipe executora, formada por pesquisadores que atuam na investigação dos temas da participação política, redes sociais, movimentos sociais, além dos temas da educação popular e juventude. Desta forma, espera-se que este projeto de extensão possa dialogar com as iniciativas de pesquisa já em andamento, de forma que elas possam se alimentar mutuamente.

Esta proposta extensionista buscou se constituir como espaço para a formação dos estudantes da Unifal-MG ao inseri-los na realidade local e ao propiciar um espaço de encontro entre universidade e sociedade. Tal encontro será sempre norteado pelos preceitos da educação para a cidadania, do respeito aos direitos humanos e às diferenças, da tomada de consciência 
da realidade social sul mineira. Pretende, portanto, formar os estudantes universitários no diálogo com a sociedade e seus múltiplos desafios na contemporaneidade. Do ponto de vista do impacto social, pretende-se estabelecer ações permanentes vinculadas à educação política democrática na região sul de Minas, contribuindo para a superação de situações de exclusão e defesa dos valores e direitos democráticos fundamentais.

O Observatório da Democracia se constituiu a partir da experiência de articulação entre saber acadêmico e saber local, com vistas à democratização do acesso ao conhecimento e à formação política cidadã. Nesta proposta de extensão universitária, foi fundamental a concepção freiriana fundamentada na construção do conhecimento como processo comunicativo e dialógico. Por isto mesmo, esta proposta extensionista pretendeu manter o formato de gestão participativa de experiências anteriores, sendo conduzida por uma comissão formada por professores, estudantes, agentes públicos e membros da comunidade nela envolvida.

De maneira geral, a metodologia desta proposta de extensão se associa às propostas de pesquisa-ação e metodologias participativas desenvolvidas no âmbito dos movimentos populares brasileiros. No início de cada ano do projeto, foi realizada a definição da Comissão Política Pedagógica (CPP), composta por professores, estudantes, representantes de associações civis e agentes públicos da região nela envolvidas. A composição da CPP e seu próprio planejamento variaram em função da definição dos eixos temáticos do Parlamento Jovem Minas a cada ano. Em 2018, quando o tema foi "Violência contra a Mulher", a única vereadora da cidade de Alfenas e o Coletivo de Mulheres da cidade de Alfenas participaram mais ativamente da CPP. No ano seguinte, quando o tema foi "Relações Étnico-Raciais", o Movimento Negro de Alfenas participou mais ativamente. Na metodologia adotada, portanto, coube à Comissão Política Pedagógica (CPP) o trabalho de planejamento, gestão, acompanhamento e avaliação do projeto.

Como já observado, este projeto de extensão pretende auxiliar e fomentar o estabelecimento de canais de diálogo entre o conhecimento produzido nas universidades, estudantes secundaristas, representantes dos legislativos municipais e membros da sociedade civil organizada, em ações que pretendem valorizar espaços de formação e educação política democrática. Parte, portanto, do pressuposto de que a dimensão política da vida em sociedade constitui uma das mais importantes e influentes esferas de nossa ação, merecendo, portanto, constituir-se como objeto de debate, reflexão, educação e aprimoramento para o desenvolvimento da democracia.

Neste sentido, o projeto desenvolveu três ações principais:

1) Parlamento Jovem de Alfenas - ação que pode ser considerada como norteadora do projeto para o ano de 2019, o Parlamento Jovem constitui-se como ação de educação política desenvolvida com os estudantes do ensino médio pela Assembleia Legislativa de Minas Gerais, em parceria com as câmaras municipais mineiras. Amplamente reconhecido por seus notáveis resultados, o Parlamento Jovem adotou, recentemente, uma estrutura de organização em rede através de uma concepção de projeto compartilhada entre a Escola do Legislativo, câmaras municipais parceiras e instituições de ensino. Alfenas aderiu ao Parlamento Jovem Minas em 2018, reali- 
zando sua primeira experiência em parceria com a Unifal-MG. A avaliação do sucesso dessa experiência gerou a demanda da Câmara Municipal para que a ação prossiga e se torne permanente, com o apoio dessa universidade. No ano de 2018, a Assembleia Legislativa de Minas Gerais escolheu como tema articulador do Parlamento Jovem Minas a questão da "Violência contra a Mulher". Em 2019, o tema articulador foi "Violência contra a Mulher". O projeto Observatório da Democracia organizou, em cada ano, um ciclo de 10 oficinas municipais e a plenária municipal que compôs o Parlamento Jovem de Alfenas. Contribuiu, também, para a realização da plenária regional, que se realizou nas cidades de Varginha e Três Corações. Contribuiu, ainda, para a plenária estadual do Parlamento Jovem Minas, com a presença de estudantes de Alfenas em Belo Horizonte, nos anos de 2018 e 2019.

2) Descomplicando a política - essa ação pretendeu produzir áudios, imagens e pequenos vídeos em torno dos direitos humanos, democracia e direitos fundamentais. No primeiro ano, em especial pequenos áudios foram produzidos por professores da UnifalMG sobre temas políticos, grande parte aproveitando o material produzido pela ALMG para o Parlamento Jovem, veiculando-se esses áudios nos intervalos da rádio comunitária do bairro Pinheirinhos. No segundo ano do projeto, os próprios estudantes secundaristas produziram pequenos vídeos sobre o tema central do PJ, que foram compartilhados nas redes sociais pelos jovens participantes numa tentativa de aproximar a defesa dos direitos humanos fundamentais a uma linguagem mais próxima da juventude.

3) Observatório da Democracia: Debates - ação voltada para o público acadêmico e comunidade em geral, através da qual foram organizadas três mesas redondas em 2018 e mais $3 \mathrm{em}$ 2019. Mais uma vez, os temas das mesas foram orientados pelos subtemas do PJ para esse anos, ou seja, abordaram o tema "Violência contra a Mulher" em 2018 e "Discriminação Étnico- Racial" em 2019. Algumas dessas mesas ocorreram no espaço da Câmara Municipal de Alfenas e outras no espaço da Universidade Federal de Alfenas.

\section{Possibilidades e desafios}

O Parlamento Jovem de Alfenas acompanhou cerca de 21 estudantes no ano de 2018, oriundos de diferentes escolas do ensino médio da cidade. Foram realizadas 10 oficinas que abordaram subtemas do tema "Violência contra a Mulher", ofertadas por professoras da Unifal-MG, representantes do Coletivo de Mulheres de Alfenas, pela vereadora da Câmara e por estudantes monitores da Unifal-MG. Cinco desses estudantes participaram da etapa regional em Varginha e dois participaram, posteriormente, da etapa estadual em Belo Horizonte.

Por meio da ação "Descomplicando a Política", foram produzidos 17 pequenos áudios, narrados por diferentes professoras e professores da Unifal-MG, que abordaram temas de educação política em geral e o próprio tema do PJ. Tais áudios foram veiculados nos inter- 
valos da rádio comunitária Pinheirinho. Havia a intenção de, nesta ação, promover entrevistas mensais com os vereadores, mas esta ação, especificamente, não foi acolhida pela Câmara.

A ação "Observatório da Democracia - Debates" realizou 3 mesas redondas com 3 convidadas relacionadas ao tema do PJ, em 2018. Assim, estiveram presentes, na primeira mesa, a delegada responsável pela Delegacia de Mulheres de Alfenas; na segunda, uma conselheira do Conselho Estadual das Mulheres de Minas; e, na terceira mesa, a Secretária Municipal de Ação Social de Direitos Humanos e a Diretora da Casa da Mulher de Alfenas.

Em 2019, o PJ foi acompanhado por 19 estudantes do ensino médio, em 10 oficinas oferecidas por professores da Unifal-MG, membros do Movimento Negro de Alfenas e monitores estudantes da Unifal-MG. Cinco destes estudantes participaram das plenárias regionais em Varginha e 2 participaram da plenária estadual em Belo Horizonte. No "Descomplicando a política", os próprios estudantes secundaristas produziram pequenos vídeos que abordaram subtemas do PJ para compartilhamento nas redes sociais. Mais uma vez, o "Observatório da Democracia - Debates" realizou 3 mesas redondas, contando com as presenças de representantes do Movimento Negro de Alfenas e de 1 professora convidada da UFMG.

Nestes dois anos de experiência, o Observatório da Democracia vivenciou as possibilidades de um projeto de extensão que se articula em torno do Parlamento Jovem de Minas. Neste sentido, o projeto pôde contar com a estrutura e com a produção da Escola do Legislativo da ALEMG não apenas para o PJ, mas também nas outras ações do projeto. Acompanhar o eixo temático do PJ possibilitou a coerência da elaboração das atividades no calendário de um ano, o contato com diferentes abordagens e produções sobre uma mesma temática em sua complexidade. Mas, ainda mais importante, desenvolver um projeto de extensão articulado pelo PJ permitiu o encontro entre universidade, juventude secundarista, agentes públicos e organizações da sociedade civil. As parcerias entre ALEMG, Câmara Municipal e universidade tornaram possível momentos de encontro e reflexão entre gestores públicos e sociedade organizada, que puderam ser acompanhados por jovens em processo de construção política. Neste aspecto, a escolha do projeto por se desenvolver tomando como seu eixo orientador o PJ foi muito acertado.

Mas, da experiência, é possível também apontar os desafios que um projeto com esse tipo de abordagem ainda precisa enfrentar. Em especial, o problema do ainda baixo invéstimento das Câmaras Municipais em ações continuadas de educação política. É verdade que, em muitas cidades, as Câmaras organizaram suas próprias Escolas do Legislativo e contam com um cronograma constante de ações educativas. Na maioria das cidades, no entanto, ações de educação política não constam no orçamento das Câmaras e não contam com funcionários específicos para esse tipo de função. Em muitos casos, as ações ocorrem pela perseverança de funcionários que exercem outras atividades e não têm, no processo educativo, sua atividade principal.

A presença de uma estrutura de educação política nas Câmaras Municipais poderia contribuir para resolver o problema de articulação da Câmara Municipal com as escolas onde estão a juventude que projetos dessa natureza pretendem alcançar. Escolas do Legislativo frequentemente mantêm contato com diretores, professores e grêmios estudantis, através dos quais ações são planejadas e realizadas. Sem essa estrutura, a articulação da Câmara com as escolas e, consequentemente, com os jovens, se torna mais difícil de ser realizada. 


\section{Conclusão}

Este relato procurou apresentar o projeto de extensão Observatório da Democracia de Alfenas, ao mesmo tempo em que procurou realizar uma reflexão sobre suas possibilidades e desafios. Foi descrita a articulação das ações do projeto através do Parlamento Jovem como sua característica central. Desta característica, decorrem suas possibilidades na realização de parcerias entre diferentes instituições e organizações da sociedade civil, em torno de práticas de educação política em direitos humanos. Neste aspecto, essa característica do projeto abre uma ampla gama de possibilidades para ações de educação que valorizem práticas democráticas e experiências de respeito e tolerância.

Por outro lado, observou-se que um projeto articulado pelo Parlamento Jovem se vê obrigado a lidar com o desafio do ainda baixo investimento em ações de educação política por parte da maioria das Câmaras Municipais brasileiras. Uma das consequências desse problema seria o distanciamento das Câmaras em relação às escolas onde estão os jovens, público prioritário de ações dessa natureza.

Tais desafios, no entanto, não devem, jamais, desmerecer a importância que o processo de educação democrática possui, especialmente em sociedades desiguais e injustas, como a brasileira e, ainda mais, obscurecer o papel fundamental que as universidades devem cumprir no auxílio ao aprofundamento de uma cultura democrática no país.

\section{Referências}

AVRITZER, Leonardo. Reforma Política e Participação no Brasil. In: ARITZER, Leonardo; ANASTASIA, Fátima (Orgs.). Reforma Política no Brasil. Belo Horizonte: Ed. UFMG. 2006.

ALMOND, Gabriel; VERBA, Sidney. The civic culture: political attitudes and democracy in five nations. Princeton: Princeton University Press, 1989.

BARROS, Antônio; MARTINS, Lúcio. Impactos do Parlamento Jovem Brasileiro na motivação e participação política partidária dos egressos. Revista Debates, Porto Alegre, v. 10, n. 2, p. 95-120, maio/ago. 2016.

BRASIL. [Constituição (1988)]. Constituição da República Federativa do Brasil: promulgada em 5 de outubro de 1988. Brasília: Senado Federal, 2020. Disponível em: https://www2.senado.leg.br/bdsf/bitstream/handle/id/566968/CF88_EC105_livro.pdf. Acesso em: 6 jun. 2021.

CAMPBELL, David E. Voice in the Classroom: How an Open Classroom Climate Fosters Political Engagement Among Adolescents. Political Behavior, Stanford, n. 30, p. 437-454, ago. 2008.

CASTRO, Ruth; FREITAS, Fernanda. Educação em rede: o exemplo do Parlamento Jovem de Minas. Belo Horizonte: Escola do Legislativo, 2017. 
COSSON, Rildo. Escolas do legislativo: escolas de democracia. Brasília: Edições Câmara, 2008.

DAHL, R. On Democracy. New Haven: Yale University Press, 1998.

FELIPPE, Wanderley. O Parlamento Jovem na extensão da PUC Minas. In: MEDEIROS, Regina; MARQUES, Maria (Orgs.). Educação política da juventude: a experiência do Parlamento Jovem. Belo Horizonte: Editora da PUC, 2012.

FINKEL, Steven E.; SMITH, Amy Erica. Civic Education, Political Discussion and the Social Transmission of Democratic Knowledge and Values in a New Democracy: The 2002 Kenya. American Journal of Political Science, New York, v. 55, n.2, p. 417-435, mar. 2010.

FREIRE, Paulo. Extensão ou Comunicação? São Paulo: Brasiliense, 1998.

MEDEIROS, Regina; MARQUES, Maria (Orgs.). Educação política da juventude: a experiência do Parlamento Jovem. Belo Horizonte: Editora da PUC, 2012.

SCHERERWARREN, Ilse. Das mobilizações às redes de movimentos sociais. Sociedade e Estado, Brasília, v. 21, n. 1, agosto, 2006.

\footnotetext{
Notas

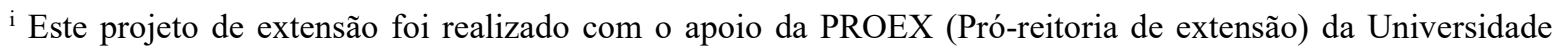
Federal de Alfenas (MG).

ii É interessante notar que a valorização da participação política popular está amplamente disseminada também na legislação infraconstitucional, ou seja, nas normas que não estão na Constituição e são hierarquicamente inferiores às normas constitucionais. Exemplo disso é o chamado Estatuto das Cidades, que regulamenta as políticas urbanas no Brasil e exige ampla participação popular no planejamento urbano.

iii Ver, por exemplo, FINKEL; SMITH (2010), MEDEIROS; MARQUES (2012); BARROS; MARTINS (2016).
} 